\title{
Composição mineral de leguminosas forrageiras cultivadas sob diferentes níveis de sombreamento
}

\section{Mineral composition of legumes forages cultivated under different levels of shade}

\author{
João Carlos de Carvalho Almeida ${ }^{1 *}$; Norberto Silva Rocha ${ }^{2}$; \\ Delci de Deus Nepomuceno²; Raphael Pavesi Araújo²; Tatiana Oliveira da Silva²; \\ Mirton José Frota Morenz $z^{3}$; João Batista Rodrigues de Abreu ${ }^{1}$; \\ Carlos Augusto Brandão de Carvalho ${ }^{1}$; Robert de Oliveira Macedo ${ }^{1}$
}

\begin{abstract}
Resumo
Objetivou-se neste estudo avaliar a composição de cálcio, fósforo e potássio e, a relação folha/haste de quatro leguminosas forrageiras tropicais: Calopogonium mucunoides (calopogônio), Pueraria phaseoloides (kudzu tropical), Macrotyloma axillare (macrotiloma) e Neonotonia wightii (soja perene), submetidas a diferentes níveis de sombreamento artificiais $(0,30,50$ e 70\%), nas estações de verão e outono dos anos de 2006 e 2007, respectivamente. O delineamento experimental utilizado foi em blocos completos casualizados em esquema fatorial $4 \times 4$, com quatro repetições. Utilizou-se o teste SNK a $5 \%$ de probabilidade para avaliar o efeito da espécie leguminosa e análise de regressão para testar o efeito do nível de sombreamento. Houve uma tendência de aumento na concentração dos 3 minerais avaliados independentes da estação do ano. Em contrapartida, ocorreu redução na relação folha/haste e um ligeiro aumento na área foliar específica do macrotiloma, kudzu tropical e soja perene $\left(\mathrm{R}^{2} \cong 40 \%\right)$, o que sugere pouco efeito do sombreamento sobre a morfologia das folhas destas 3 leguminosas, que por sua vez apresentam pouco efeito concentrador de minerais, além destas constatação confirma-se o comportamento anual do calopogônio, o que inviabiliza seu emprego como leguminosa forrageira para a estação de outono.
\end{abstract}

Palavras-chave: Calopogonium mucunoides, Macrotyloma axillare, Neonotonia wightii Pueraria phaseoloides

\begin{abstract}
The objective of this study was to evaluate the composition of calcium, phosphorus and potassium, and the leaf: stem ratio of four tropical forage legumes: Calopogonium mucunoides (calopo), Pueraria phaseoloides (puero), Macrotyloma axillare (archer) and Neonotonia wightii (perennial soybean), under different levels of artificial shade $(0,30,50$ and $70 \%)$ in the summer and autumn seasons of 2006 and 2007 , respectively. The experimental design was a randomized complete block in factorial $4 \times 4$ design with four replications. Was used SNK test at 5\% probability to evaluate the effect of the legume species
\end{abstract}

\footnotetext{
${ }^{1}$ Profs. do Instituto de Zootecnia da Universidade Federal Rural do Rio de Janeiro, UFRRJ, Seropédica, RJ. E-mail: joaocarlosbq@ gmail.com; jbrabreu@yahoo.com.br; carloscarvalho_ufrrj@yahoo.com.br; robertmacedo1@yahoo.com.br

2 Discentes do Curso de Mestrado do Programa de Pós-Graduação em Zootecnia da UFRRJ, Seropédica, RJ. E-mail: nsrocha@, gmail.com; delci_ufrrj@yahoo.com.br; raphaelpavesi@yahoo.com.br; tatiana.zoo@gmail.com

${ }^{3}$ Pesquisador da Empresa Brasileira de Pesquisa Agropecuária, EMBRAPA, Juiz de Fora, MG. E-mail: mirtonmorenz@yahoo. com.br

*Autor para correspondência
} 
and regression analysis to test the effect of the level of shading. There was a trend of increase in the concentration of 3 independent minerals examined the season. In contrast, there was a reduction in the leaf: stem ratio and a slight increase in specific leaf area archer, perennial soybean and puero $\left(\mathrm{R}^{2} \cong\right.$ $40 \%$ ), which suggests small effect of shading on the morphology of leaves of 3 forage legumes, which in turn have little effect concentrating minerals, besides these finding is confirmed the annual calopo behavior, which prevents their use as legume forage for the autumn season.

Key words: Calopogonium mucunoides, Macrotyloma axillare, Neonotonia wightii Pueraria phaseoloides

\section{Introdução}

A competitividade dos tempos modernos tem resultado, muitas vezes, em práticas agressivas ao meio ambiente. Os sistemas Agroflorestais (SAFs), pautados no conceito de sustentabilidade da atividade agropecuária, constituem alternativa interessante para a utilização racional das áreas cultivadas.

Segundo Ferreira (2005), os SAFs tentam proporcionar um rendimento mais sustentável ao longo do tempo, introduzindo espécies arbóreas anuais nos primeiros anos, seguidas de espécies frutíferas semiperenes e perenes e/ou madeiráveis, os quais podem ainda, ser consorciadas com animais em uma mesma área. Esta última prática, denominada de sistemas silvipastoris (SSPs), tem apresentado resultados satisfatórios quanto a sua utilização, atribuídos principalmente às questões como: conforto térmico animal, reciclagem de nutrientes e sequestro de carbono.

O sombreamento resultante da comunidade arbórea sobre a comunidade forrageira pode ser apontado como um dos principais fatores limitantes à produtividade destes sistemas. Em gramíneas são reportados: decréscimo na produção de matéria seca (GOBBI et al., 2009), e aumento de Fibra e lignina em detergente ácido (SENANAYAKE, 1995) e de proteína bruta (GOBBI et al., 2010). Outras alterações que podem ocorrer em plantas cultivadas sob condições de luminosidade reduzida são: alterações morfofisiológicas (GOBBI et al., 2010), incremento ou redução na produção forrageira (PACIULLO et al., 2007) e acréscimo na composição mineral desses vegetais (CARVALHO;
FREITAS; ANDRADE， 1995; CARVALHO; SILVA; CAMPOS JÚNIOR, 1997; ANDRADE et al., 2004). No entanto, os efeitos do sombreamento sobre as características morfológicas e produção de matéria seca das forragens são dependente da espécie e do nível de sombreamento (CASTRO et al., 1999; GOBBI et al., 2010).

Leguminosas forrageiras tropicais constituem alternativa para intensificar a produção agropecuária nos trópicos, uma vez que contribuem com a incorporação do nitrogênio atmosférico ao solo e constituem uma importante fonte nutricional para o animal, devido maior teor proteico, qualidade da fibra e sua composição mineral em relação às gramíneas (BARCELLOS et al., 2008). Segundo Carvalho e Pires (2008), incrementos na produtividade animal são observados quando as leguminosas são introduzidas no sistema produtivo, constituindo uma alternativa promissora para produção orgânica tanto na pecuária de corte quanto na atividade leiteira.

Entretanto, é necessário identificar as espécies que toleram melhor o cultivo sob sombreamento, bem como os níveis de sombreamento que interfere sobre a forragem para obter as vantagens oferecidas pelo consórcio existente no SSP (SOARES et al., 2009).

Devido o exposto, objetivou-se com este estudo avaliar os níveis de sombreamento $(0,30,50$ e $70 \%$ de retenção luminosa) sobre a composição mineral (porcentagem de cálcio, fósforo e potássio) e relação folha/haste das leguminosas Calopogonium mucunoides (calopogônio), Pueraria phaseoloides (kudzu tropical), Macrotyloma axillare 
(macrotiloma) e Neonotonia wightii (soja perene).

\section{Materiais e Métodos}

O experimento foi conduzido no setor de Forragicultura do Departamento de Nutrição Animal e Pastagem, pertencente ao Instituto de Zootecnia da Universidade Federal Rural de Rio de Janeiro, Seropédica, Rio de Janeiro - Brasil (22 46 $27^{\prime \prime}$ $\mathrm{S}$ e $43^{\circ} 41^{\prime} 11^{\prime \prime} \mathrm{O} ; 22 \mathrm{~m}$ de altitude) no período de dezembro de 2006 a junho de 2007. Utilizando para isto, um delineamento experimental em blocos completos casualizados, em esquema fatorial $4 \mathrm{x} 4$ com 4 repetições. Submetendo-se as leguminosas calopogônio, kudzu tropical, macrotiloma e soja perene a quatro níveis de sombreamento $(0,30$, 50 e $70 \%$ de retenção luminosa) com telas de polipropileno fixadas a uma altura de $1,60 \mathrm{~m}$ do solo.

O solo da área experimental apresentava antes da fertilização as seguintes características na camada de 0-20 cm: $\mathrm{Ca}^{++} 2,2 \mathrm{Cmol}_{\mathrm{c}} / \mathrm{dm}^{3}, \mathrm{Mg}^{++} 1,5 \mathrm{Cmol}_{\mathrm{c}} /$ $\mathrm{dm}^{3}, \mathrm{Al}^{+++} 0,0 \mathrm{Cmol}_{\mathrm{c}} / \mathrm{dm}^{3}, \mathrm{P} 7 \mathrm{mg} / \mathrm{l}, \mathrm{K} 154 \mathrm{mg} / 1, \mathrm{C}_{\text {org }}$ $0,93 \%, \mathrm{~V} 85 \%$ e pH 6,3. O clima da região é do tipo AW pela classificação de Köppen. Os dados referentes às temperaturas máximas e mínimas e precipitação pluviométrica estão apresentados na figura 1.

Figura 1. Precipitação $(\mathrm{mm})$ e Temperatura média $\left({ }^{\circ} \mathrm{C}\right)$ máxima (T. max) e mínima (T. min) dos meses experimentais.

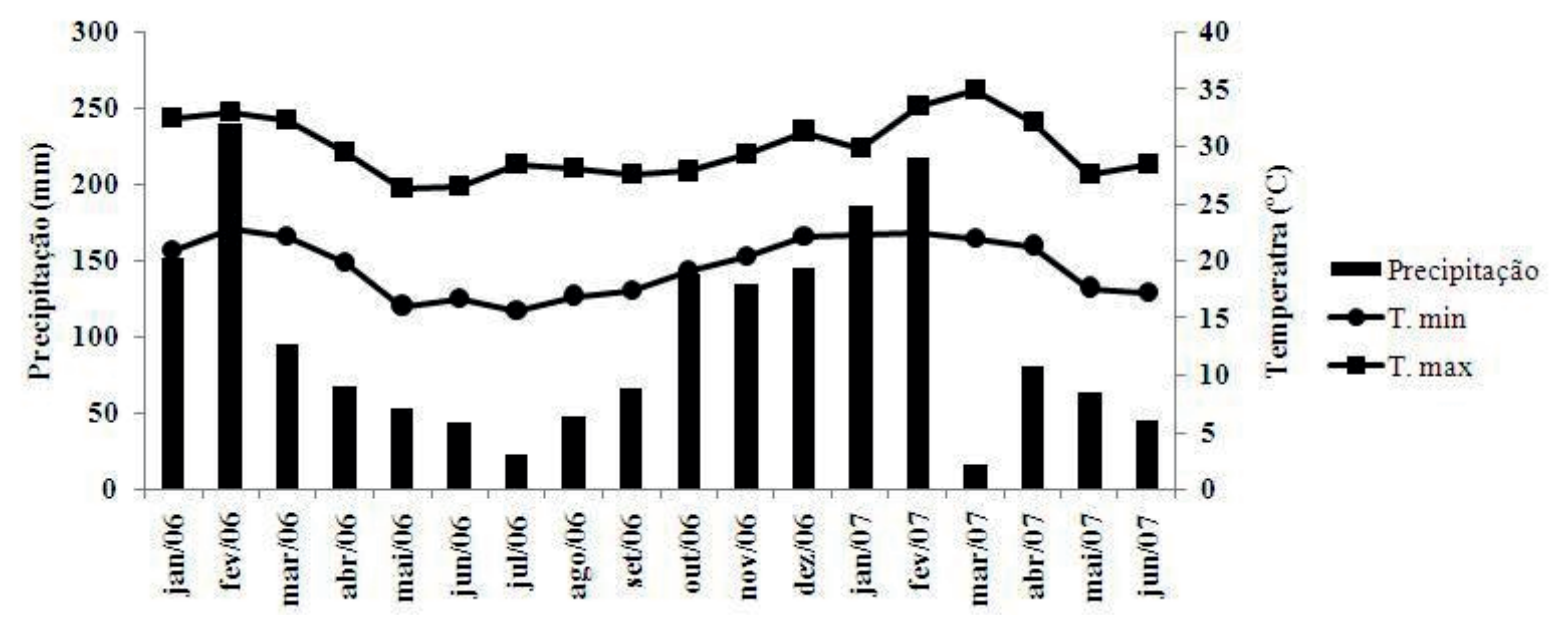

Fonte: Elaboração dos autores.

O plantio das leguminosas foi realizado em canteiros de $6 \mathrm{~m}^{2}$ constituídos por 5 linhas de 3 $\mathrm{m}$ de comprimento e espaçadas em $0,5 \mathrm{~m}$ entre si. Sendo realizadas adubações de plantio e de cobertura com equivalente a $200 \mathrm{~kg} \cdot \mathrm{ha}^{-1}$ de superfosfato simples e $100 \mathrm{~kg} \cdot \mathrm{ha}^{-1}$ cloreto de potássio. As leguminosas foram submetidas a um corte de uniformização para início das avaliações nas estações de verão e outono do ano de 2006. Os cortes foram efetuados numa área de $0,25 \mathrm{~m}^{2}$ no centro da parcela experimental, deixando uma altura de resíduo de $5 \mathrm{~cm}$ quando as leguminosas apresentavam 90 dias de crescimento.

O material foi amostrado em 3 subamostras, referentes à folha, haste e planta inteira. Em seguida pesado, acondicionados em sacos de papel e secos em estufa de ventilação forçada $\left(60 \pm 5{ }^{\circ} \mathrm{C}\right.$; por 72 h). Com este material, determinou-se a relação folha/haste e porcentagem de cálcio $(\% \mathrm{Ca})$, fósforo $(\% \mathrm{P})$ e potássio $(\% \mathrm{~K})$, segundo a metodologia 
descrita por Tedesco et al. (1995).

Os dados qualitativos referentes à variável leguminosas foram submetidos à análise de variância (Teste $F, \alpha=0,05$ ) e as médias comparadas, utilizando-se o teste Student-Newman-Keuls (SNK) a 5\% de probabilidade. Enquanto os dados quantitativos referentes à variável sombreamento, submetidos à análise de regressão, utilizando-se o pacote estatístico SAEG - Sistema para Análises Estatística e Genética - (UFV, 2001), de acordo com a análise de variância.

\section{Resultados e Discussão}

A porcentagem dos minerais $(\mathrm{Ca}, \mathrm{KeP})$ estudados apresentou incrementos em relação à fração da planta (planta inteira, folha e haste) e estações do ano (verão e outono) e níveis de sombreamento, conforme apresentado pelas respectivas equações de regressões para cada mineral. No verão, a porcentagem de fósforo $(\mathrm{P})$ na porção planta inteira e cálcio $(\mathrm{Ca})$ na fração folha das leguminosas não diferiram pelos níveis de sombreamento $(\mathrm{P}>0,05)$. No entanto, ocorreu efeito de interação leguminosaníveis de sombreamento $(\mathrm{P}<0,05)$ (TabelaS 1 e 2$)$.

Tabela 1. Médias \pm desvios-padrão, equação de regressão e coeficiente de determinação $\left(\mathrm{R}^{2}\right)$ da porcentagem de fósforo $(\mathrm{P})$ presente na planta inteira das leguminosas forrageiras submetidas aos níveis de sombreamento $(0,30,50$ e $70 \%)$.

\begin{tabular}{|c|c|c|c|c|c|c|}
\hline \multirow{2}{*}{ Espécie } & \multicolumn{4}{|c|}{ Sombreamento } & \multirow{2}{*}{ Equação de regressão } & \multirow{2}{*}{$\mathbf{R}^{2}$} \\
\hline & $0 \%$ & $30 \%$ & $50 \%$ & $70 \%$ & & \\
\hline $\mathrm{Cal}^{1}$ & $0,12 \pm 0,02 \mathrm{a}$ & $0,13 \pm 0,01 \mathrm{ab}$ & $0,13 \pm 0,01 \mathrm{a}$ & $0,16 \pm 0,01 \mathrm{a}$ & $\mathrm{Y}=0,123281-6,6 * 10^{-5} \mathrm{X}+9,0 * 10^{-6} \mathrm{X}^{2}$ & 96,0 \\
\hline $\mathbf{K \mathbf { t } ^ { 2 }}$ & $0,11 \pm 0,02 \mathrm{a}$ & $0,13 \pm 0,01 \mathrm{ab}$ & $0,15 \pm 0,02 \mathrm{a}$ & $0,17 \pm 0,01 \mathrm{a}$ & $\mathrm{Y}=0,10972+8,57^{*} 10^{-4} \mathrm{X}$ & 99,0 \\
\hline $\mathbf{M a c}^{3}$ & $0,10 \pm 0,01 \mathrm{a}$ & $0,11 \pm 0,01 \mathrm{~b}$ & $0,14 \pm 0,01 \mathrm{a}$ & $0,18 \pm 0,01 \mathrm{a}$ & $\mathrm{Y}=0,104805-4,6 * 10^{-5} \mathrm{X}+1,7 * 10^{-5} \mathrm{X}^{2}$ & 99,0 \\
\hline $\mathrm{Sp}^{4}$ & $0,12 \pm 0,01 \mathrm{a}$ & $0,14 \pm 0,01 \mathrm{a}$ & $0,15 \pm 0,02 \mathrm{a}$ & $0,16 \pm 0,02 \mathrm{a}$ & $\mathrm{Y}=0,125748+5,47 * 10^{-4} \mathrm{X}$ & 99,0 \\
\hline
\end{tabular}

Médias seguidas das mesmas letras, nas colunas, não diferem entre si pelo teste $\mathrm{SNK}(\mathrm{P}>0,05)$; ${ }^{1}$ Calopogonium mucunoides; ${ }^{2}$ Pueraria phaseoloides; ${ }^{3}$ Macrotyloma axillare; ${ }^{4}$ Neonotonia wightii.

Fonte: Elaboração dos autores.

Tabela 2. Médias \pm desvios-padrão, equação de regressão e coeficiente de determinação $\left(\mathrm{R}^{2}\right)$ da porcentagem de cálcio $(\mathrm{Ca})$ nas folhas das leguminosas forrageiras submetidas a níveis de sombreamento $(0,30,50 \mathrm{e}$ $70 \%)$.

\begin{tabular}{|c|c|c|c|c|c|c|}
\hline \multirow{2}{*}{ Espécie } & \multicolumn{4}{|c|}{ Sombreamento } & \multirow{2}{*}{ Equação de regressão } & \multirow{2}{*}{$\mathbf{R}^{2}$} \\
\hline & $0 \%$ & $30 \%$ & $50 \%$ & $70 \%$ & & \\
\hline $\mathrm{Cal}^{1}$ & $0,36 \pm 0,01 \mathrm{a}$ & $0,39 \pm 0,02 \mathrm{a}$ & $0,41 \pm 0,02 \mathrm{a}$ & $0,46 \pm 0,02 b$ & $\mathrm{Y}=0,357780+1,39 * 10^{-3} \mathrm{X}$ & 94,9 \\
\hline $\mathbf{K t}^{2}$ & $0,33 \pm 0,04 \mathrm{a}$ & $0,37 \pm 0,03 \mathrm{a}$ & $0,43 \pm 0,04 \mathrm{a}$ & $0,48 \pm 0,05 \mathrm{ab}$ & $Y=0,325117+2,16^{*} 10^{-3} X$ & 98,0 \\
\hline $\mathbf{M a}^{3}$ & $0,31 \pm 0,03 \mathrm{a}$ & $0,36 \pm 0,04 a$ & $0,41 \pm 0,04 \mathrm{a}$ & $0,48 \pm 0,02 \mathrm{ab}$ & $Y=0,308107+2,35 * 10^{-3} \mathrm{X}$ & 96,8 \\
\hline $\mathbf{S p}^{4}$ & $0,31 \pm 0,02 \mathrm{a}$ & $0,34 \pm 0,03 \mathrm{a}$ & $0,44 \pm 0,02 \mathrm{a}$ & $0,53 \pm 0,04 \mathrm{a}$ & $Y=0,286589+3,22 * 10^{-3} X$ & 91,9 \\
\hline
\end{tabular}

Médias seguidas das mesmas letras, nas colunas, não diferem entre si pelo teste SNK 183 (P>0,05); ${ }^{1}$ Calopogonium mucunoides; ${ }^{2}$ Pueraria phaseoloides; ${ }^{3}$ Macrotyloma axillare; ${ }^{4}$ Neonotonia wightii.

Fonte: Elaboração dos autores.

Ao desdobrar a interação entre frações da menor concentração de fósforo do macrotiloma leguminosa e níveis de sombreamento, observou- em relação ao da soja perene. Enquanto que se ao nível de $30 \%$ de sombreamento uma a fração folha do calopogônio apresentou 
menor concentração de $\mathrm{Ca}$ ao nível de $70 \%$ de sombreamento em relação ao da fração folha da soja perene $(\mathrm{P}<0,05)$.

A leguminosa calopogônio apresentou comportamento anual, não ocorrendo rebrote após o corte no verão, o que corrobora com o observado por Pádua et al. (2004) que relataram o comportamento anual desta leguminosa na região estudada. Assim, só as leguminosas, soja perene, macrotiloma e kudzu tropical foram avaliadas nesta estação. Sendo que, ocorreu efeito de interação entre leguminosas $x$ níveis de sombreamento na determinação da \% P na fração planta inteira $(\mathrm{P}<0,05)$ Tabela 3 .

No outono, ao nível de $30 \%$ de sombreamento foi observado menor proporção de fósforo da soja perene em relação ao kudzu tropical e macrotiloma. E ao nível de $70 \%$ de sombreamento as três leguminosas diferiam quanto à concentração deste mineral sendo que o macrotiloma apresentou maior concentração $(\mathrm{P}<0,05)$.

Tabela 3. Médias e seus respectivos desvios-padrão, equação de regressão e coeficiente de determinação $\left(\mathrm{R}^{2}\right)$ da porcentagem de fósforo $(\mathrm{P})$ presente na planta inteira das leguminosas forrageiras tropicais submetidas a níveis de sombreamento $(0,30,50$ e $70 \%$ de retenção luminosa), durante o outono.

\begin{tabular}{|c|c|c|c|c|c|c|}
\hline \multirow{2}{*}{ Espécie } & \multicolumn{4}{|c|}{ Sombreamento } & \multirow{2}{*}{ Regressão } & \multirow{2}{*}{$\mathbf{R}^{2}$} \\
\hline & $0 \%$ & $30 \%$ & $50 \%$ & $70 \%$ & & \\
\hline $\mathbf{K} \mathbf{t}^{1}$ & $0,11 \pm 0,01 \mathrm{a}$ & $0,13 \pm 0,02 \mathrm{a}$ & $0,15 \pm 0,01 \mathrm{a}$ & $0,15 \pm 0,01 b$ & $\mathrm{Y}=0,107+7,58^{*} 10^{-4} \mathrm{X}$ & 93,9 \\
\hline $\mathbf{M a}^{2}$ & $0,12 \pm 0,01 \mathrm{a}$ & $0,14 \pm 0,01 \mathrm{a}$ & $0,16 \pm 0,03 \mathrm{a}$ & $0,17 \pm 0,02 \mathrm{a}$ & $Y=0,118+9,19 * 10^{-4}$ & 96,2 \\
\hline $\mathbf{S p}^{3}$ & $0,13 \pm 0,01 \mathrm{a}$ & $0,14 \pm 0,02 \mathrm{a}$ & $0,13 \pm 0,02 b$ & $0,13 \pm 0,01 \mathrm{c}$ & $Y=0,131+3,1 * 10^{-4} X-6^{*} 10^{-6} X^{2}$ & 58,0 \\
\hline
\end{tabular}

${ }^{1}$ Pueraria phaseoloides; ${ }^{2}$ Macrotyloma axillare; ${ }^{3}$ Neonotonia wightii.

Fonte: Elaboração dos autores.

Excetuando as interações citadas nas tabelas 1,2 e 3, para as demais frações avaliadas não houve efeito $(\mathrm{P}>0,05)$ de leguminosas, níveis de sombreamento e interação entre estas duas variáveis, sobre a \% dos minerais determinados em ambas às estações. No entanto, houve efeito de níveis de sombreamento nas duas estações sobre a \% dos minerais estudados nas três frações, marcado pelo aumento linear do teor dos minerais nas leguminosas $(\mathrm{P}<0,05)$ Figura 2 .

A luminosidade não atua diretamente na absorção de elementos minerais no vegetal, todavia influencia processos biologicamente passíveis de alteração da concentração destes nutrientes na planta, tais como: fotossíntese, transpiração e respiração, uma vez que as plantas acumulam íons contra gradiente de concentração (CLARK, 1981). Assim, a luz convertida em energia pelo vegetal influencia na absorção dos nutrientes minerais e na sua concentração.

Castro et al. (2001) relataram tendência de aumento nos teores dos minerais $\mathrm{P}, \mathrm{K}, \mathrm{Ca}$ e $\mathrm{Mg}$, em Brachiaria brizantha, cv. Marandu; B. decumbens; Melinis minutiflora; Andropogon gayanus, cv. Planatina; Panicum maximum, cv. Vencedor; e Setaria sphacelata, cv. Kazungula, submetidas aos níveis 0,30 e $60 \%$ de sombreamento.

Embora, seja relatada a estímulo da luminosidade sobre o teor de $\mathrm{P}$, através da absorção de $\mathrm{H}_{2} \mathrm{PO}_{4}$, há controvérsias dos resultados encontrados sobre concentração deste mineral tanto em leguminosas quanto em gramíneas (CASTRO et al., 2001).

$\mathrm{O}$ teor de $\mathrm{K}$ presente nas leguminosas estudadas está de acordo com os encontrados na literatura (CARVALHO; FREITAS; ANDRADE, 1995; CASTRO et al., 2001), e que as frações folha e haste apresentaram incremento nos teores de $\mathrm{K}$ durante os dois períodos de avaliação. 
$\mathrm{O}$ incremento da $\%$ de $\mathrm{Ca}^{+2}$ não é estimulado pela luminosidade (ERIKSEN; WHITNEY, 1982), no entanto, este estudo a \% de $\mathrm{Ca}^{+2}$ apresentou influência dos níveis crescentes de sombreamento tanto na fração folha como na fração haste, nos dois períodos de avaliação. O que corrobora com Belsky (1992) que avaliou o incremento deste mineral em gramíneas submetidos ao sombreamento imposto por árvores e com Castro et al. (2001) que reportaram incremento deste mineral nas fração folha de seis gramíneas submetidas ao sombreamento artificial.

Carvalho, Freitas e Andrade (1995) ressaltaram que forrageiras cultivadas sob condições de sombreamento tendem a apresentar maior porcentagem de folhas verdes, menor porcentagem de matéria seca e maiores concentrações de nitrogênio, fósforo e potássio nas folhas do que as plantas cultivadas a sol pleno.

Figura 2. \% cálcio $\bullet$; potássio e fósforo $\bullet$ de acordo com os níveis de sombreamento no verão (A, C e E) e no outono (B, D e F).
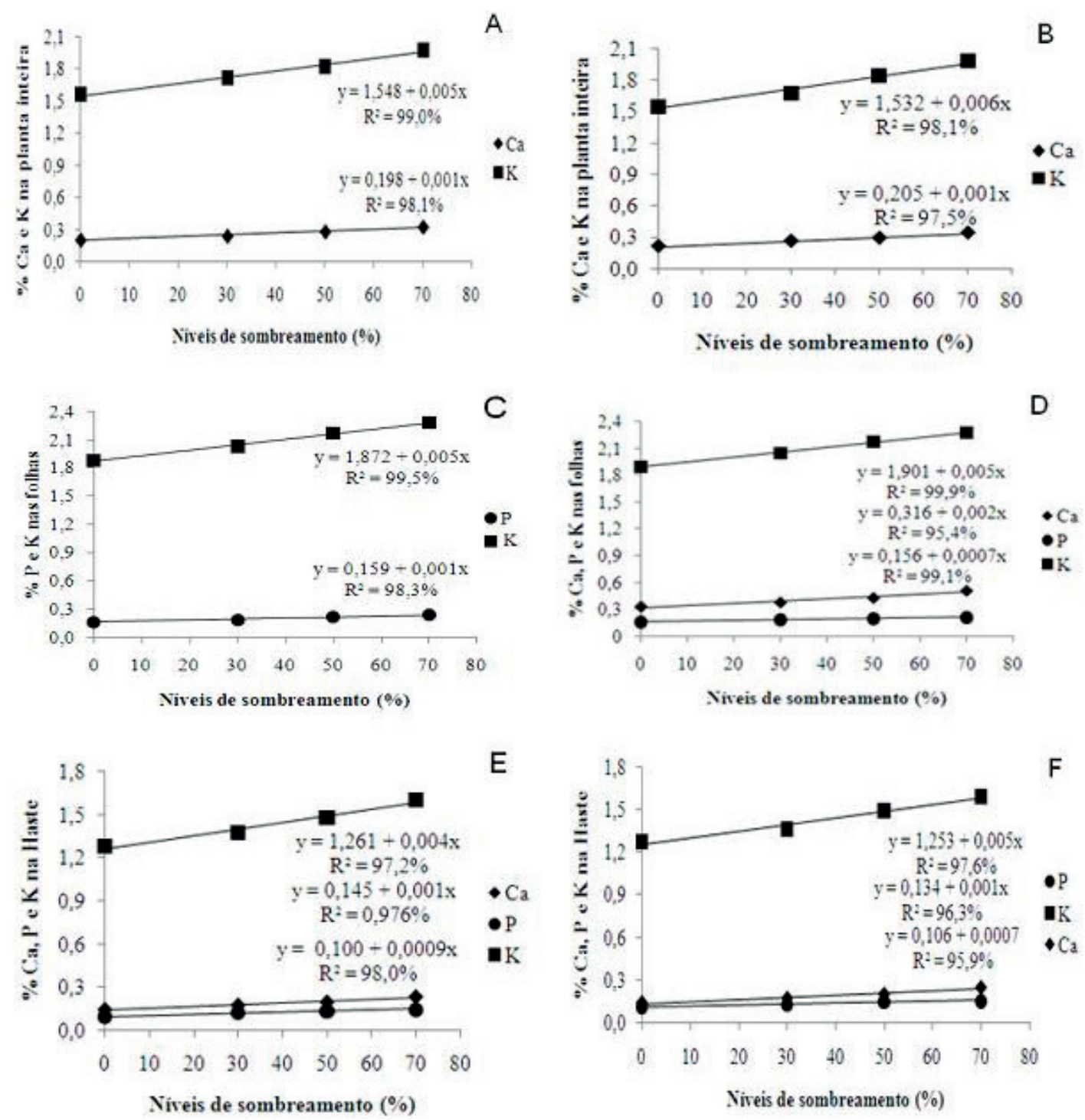

Fonte: Elaboração dos autores. 
$\mathrm{O}$ incremento dos minerais está relacionado às modificações que o sombreamento acarreta no desenvolvimento do vegetal. A redução da luminosidade incidente acarreta modificações morfofisiológicas que podem resultar em maior adaptação das plantas as condições de sombreamento. Segundo Eriksen e Whitney (1982), as leguminosas; centrosema (Centrosema pubescens), siratro (Macroptilium atropurpureum), leucena (Leucaena leucocephala), estilosantes (Stylosanthes humilis) e desmodium (Desmodium canadense) crescendo à sombra, apresentaram porte mais alto, com hastes mais grossas e folhas mais delgadas, resultando maior relação de massa/volume, quando comparada com plantas crescendo à sombra. Ribask e Menezes (2002) relataram que sob sombreamento, o vegetal tende: a reduzi a fotossíntese, porém com o aumento da eficiência fotossintética; eleva o teor de clorofila; aumenta a área foliar específica e incrementa o teor de nitrogênio na planta. Entretanto, Oliveira e Souto (2001) citam que em leguminosas o conteúdo de nitrogênio não é severamente afetado pelo sombreamento e que leguminosas tolerantes ao sombreamento mantem um balanceamento entre a proporção folha/caule em ambientes sombreados, ao mesmo tempo em que as não tolerantes geralmente reduzem a relação folha/caule sob sombra.

O microambiente proposto pelo sombreamento favorece a manutenção da fertilidade do solo o que reflete na composição mineral das forragens (CARVALHO; SILVA; CAMPOS JÚNIOR, 1997; DURR; RANGEL, 2000). A alteração no teor de minerais também pode estar relacionada a alterações morfológicas das forragens ao sombreamento (KOUKOURA; KYRIAZOPOULOS; PARISSI, 2009). Assim, o acréscimo observado nos teores dos minerais estudados, nas quatro leguminosas, neste trabalho estaria, provavelmente, relacionado às alterações morfofisiológicas proporcionadas pela ação do sombreamento.

Afirmativa está baseada na resposta apresentada pela relação folha/haste, a qual apresentou redução deste valor à medida que o nível de sombreamento foi intensificado Figura 3.

Figura 3. Relação folha/haste das leguminosas forrageiras tropicais em função dos níveis de sombreamento $(0,30,50$ e $70 \%$ de retenção luminosa), durante o verão e outono.

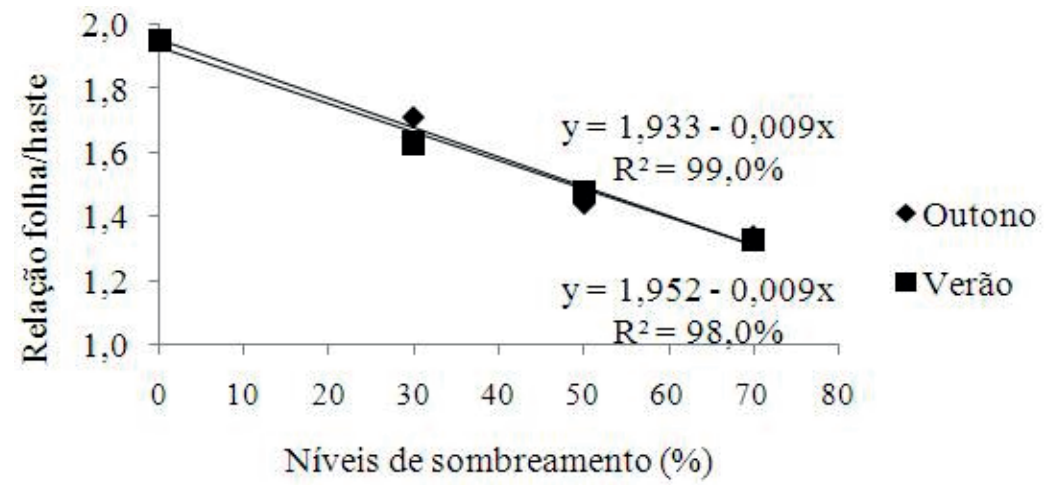

Fonte: Elaboração dos autores.

Arelação folha/haste das leguminosas forrageiras tropicais apresentou efeito linear negativo em função do nível de sombreamento (0, 30, 50 e 70\% de retenção luminosa) durante o verão e outono, onde foi observado decréscimo médio de $0,2 \%$ na relação folha/haste para cada nível de sombreamento estudado em ambas estações. Entretanto, ao avaliar a área foliar específica das folhas (Cm2/g) (AFE) das 
leguminosas obteve um coeficiente de determinação ( $\mathrm{R} 2 \cong 40 \%$ ) para as leguminosas kudzu tropical, soja perene e macrotiloma, o que sugere pouca influência do sombreamento na morfologia das folhas destas 3 leguminosas e, estas mudanças nas folhas apresentam pouco efeito concentrador de minerais.

\section{Conclusões}

O sombreamento exerce alteração na composição mineral de leguminosas forrageiras, com tendência de aumento dos minerais: cálcio, fósforo e potássio.

O sombreamento diminui a relação folha/ haste, entretanto possui pouco efeito sobre alterações morfológicas (área foliar específica) das leguminosas forrageiras tropicais avaliadas.

As alterações na concentração de fósforo, cálcio e potássio, sugere adaptações ao sombreamento o que torna estas leguminosas factíveis de serem utilizadas em sistemas silvipastoris. Entretanto, a baixa alteração na AFE das leguminosas sugere pouco efeito do sombreamento na concentração de minerais nas folhas.

O calopogônio apresenta como forrageira anual, o que torna como empecilho a sua utilização em sistema de pastagens.

\section{Agradecimentos}

À FAPERJ pelo financiamento deste projeto de pesquisa. Às Empresas Sementes Selegran e Matsuda Sementes, pelo oferecimento das sementes utilizadas no presente estudo.

\section{Referências}

ANDRADE, C. M. S.; VALENTIM, J. F.; CARNEIRO, J. C.; VAZ, F. A. Crescimento de gramíneas e leguminosas forrageiras tropicais sob sombreamento. Pesquisa Agropecuária Brasileira, Brasília, v. 39, n. 3, p. 263-270, 2004.
BARCELLOS, A. O.; RAMOS, A. K. B.; VILELA, L.; MARTHA JUNIOR, G. B. Sustentabilidade da produção animal baseada em pastagens consorciadas e no emprego de leguminosas exclusivas, na forma de banco de proteína, nos trópicos brasileiros. Revista Brasileira de Zootecnia, Viçosa, MG, v. 37, p. 51-67, 2008. Número Especial.

BELSKY, A. J. Effects of trees on nutritional quality of understore gramineous forage in tropical savannas. Tropical Grasslands, Brisbane, v. 26, n. 1, p. 12-20, 1992.

CARVAlHO, G. G. P.; PIRES, A. J. V. Leguminosas tropicais herbáceas em associação com pastagens. Archivos de Zootecnia, Córdoba, v. 57, n. 1, p. 103-113, 2008.

CARVALHO, M. M.; FREITAS, V. P.; ANDRADE, A. P. Crescimento inicial de cinco gramíneas tropicais em um sub-bosque de angico-vermelho (Anadenathera macrocarpa Benth). Pasturas Tropicales, Cali, v. 17, n. 1, p. 24-30, 1995.

CARVALHO, M.M.; SILVA, J.L. O.; CAMPOS JÚNIOR, B. A. Produção de matéria seca e composição mineral da forragem de seis gramíneas tropicais estabelecidas em sub bosque de angico-vermelho. Revista Brasileira de Zootecnia, Viçosa, v. 26, n. 2, p. 51-67, 1997.

CASTRO, C. R. T.; GARCIA, R.; CARVALHO, M. M.; COUTO, L. Produção forrageira de gramíneas cultivadas sob luminosidade reduzida. Revista Brasileira de Zootecnia, Viçosa, MG, v. 28, n. 5, p. 919-927, 1999.

CASTRO, C. R. T.; GARCIA, R.; CARVALHO, M. M.; FREITAS, V. P. Efeitos do sombreamento na composição mineral de gramíneas forrageiras tropicais. Revista Brasileira de Zootecnia, Viçosa, v. 30, n. 6, p. 19591968, 2001.

CLARK, R. B. Effect of light and water stress on mineral element composition of plants. Journal of Plant Nutrition, New York, v. 3, n. 5, p. 853-885, 1981.

DURR, P. A.; RANGEL, J. The response of Panicum maximum to a simulated subcanopy environment. I. Soil x shade interaction. Tropical Grasslands, Brisbane, v. 34, n. 1, p. 110-117, 2000.

ERIKSEN, F. I., WHITNEY, A. S. Growth and fixation of some tropical forage legumes as influenced by solar radiation regimes. Agronomy Journal, Madison, v. 74, n. 4, p. 703-709, 1982.

FERREIRA, L. M. M. Sistema agroflorestal é alternativa sustentável para produção rural. Jornal Folha de Boa Vista, Boa Vista, 27 jun, 2005. 
GOBBI, K. F.; GARCIA, R.; GARCEZ NETO, A. F.; PEREIRA, O. G.; ROCHA, G. C. Valor nutritivo do capim-braquiária e do amendoim forrageiro submetidos ao sombreamento. Archivos Zootecnia, Córdoba, v. 59, n. 227, p. 379-390, 2010.

GOBBI, K. F.; GARCIA, R.; GARCEZ NETO, A. F.; PEREIRA, O. G.; VENTRELLA, M. C.; ROCHA, G. C. Características morfológicas, estruturais e produtividade do capim-braquiária e do amendoim forrageiro submetidos ao sombreamento. Revista Brasileira de Zootecnia, Viçosa, MG, v. 38, n. 9, p 1645-1654, 2009.

KOUKOURA, Z. A.; KYRIAZOPOULOS, P.; PARISSI, Z. M. Growth characteristics and nutrient content of some herbaceous species under shade and fertilization. Spanish Journal of Agricultural Research, Madrid, v. 7, n. 2, p. 431-438, 2009.

OLIVEIRA, F. L.; SOUTO, S. M. Comportamento de leguminosas forrageiras tropicais sob sombreamento. Pesquisa Agropecuária Gaúcha, Porto Alegre, v. 8, n. 1-2, p. 67-74, 2002.

PACIUllo, D. S. C.; CARVAlHO, C. A. B.; AROEIRA, L. J. M.; MORENZ, M. J. F.; LOPES, F. C. F.; ROSSIELlO, R. O. P. Morfofisiologia e valor nutritivo do capim-braquiária sob sombreamento natural e a pleno sol. Pesquisa Agropecuária Brasileira, Brasília, v. 42, n. 4, p. 573-579, 2007.
PÁDUA, F. T.; ALMEIDA, J. C. C.; MAGIERO, J. Q.; NEPOMUCENO, D. D.; SILVA, T. O.; ROCHA, N. S. Produção de matéria seca e semente de leguminosas forrageiras tropicais cultivadas em diferentes espaçamentos. Revista Universidade Rural. Série Ciências da Vida, Seropédica, v. 24, n. 2, p. 13-20, 2004.

RIBASK, J.; MENEZES, E. A. Disponibilidad y calidad del pasto buffel (Cenchrus ciliaris) en un sistema silvopastoril con algarrobo (Prosopis juliflora) en la región semi-árida brasileña. Agroforesteria en las Américas, Turrialba, v. 9, n. 33, p. 8-13, 2002.

SENANAYAKE, S. G. J. N. The effects of different light levels on the nutritive quality of four natural tropical grasses. Tropical Grasslands, Brisbane, v. 29, n. 1, p. 111-114, 1995.

SOARES, A. B.; SARTOR, L. R.; ADAMI, P. F.; VARELLA, A. C.; FONSECA, L. F.; MEZZALIRA, J. C. Influência da luminosidade no comportamento de onze espécies forrageiras perenes de verão. Revista Brasileira de Zootecnia, Viçosa, MG, v. 38, n. 3, p. 443-451, 2009.

TEDESCO, M. J.; GIANELLO, C.; BISSANI, C. A.; BOHNEN, H.; VOLKWEISS, S. J. Análise de solo, plantas e outros materiais. 2. ed. Porto Alegre: Departamento de Solos, Universidade Federal do Rio Grande do Sul, UFRGS, 1995. 174 p.

UNIVERSIDADE FEDERAL DE VIÇOSA - UFV. SAEG - Sistema de análise estatística e genética. Viçosa, MG: UFV, 2001. 301 p. 
